\title{
Submission Guidelines for J.E.T.T. Contributors
}

The Journal of Educational Techniques and Technologies accepts manuscript submissions from prospective authors and print/electronic media products from manufacturers, distributors, and vendors. The following guidelines highlight the general submission procedures for manuscript submission (for possible publication) and product submission (for review).

\section{Manuscript Submission Guidelines for Authors}

Types of Articles: The Journal of Educational Techniques and Technologies (J.E.T.T.) publishes the following types of articles: brief reports, comments/replies, case histories, monographs, reports of empirical studies, review articles, theoretical articles, discussions of quantitative methods, issues and answers, points-of-view, tools of the trade, and feature articles in the following areas: language laboratories, media in language learning, satellite broadcasts, learning lab equipment, learning lab administration, CAI and language learning, media in business languages, languages in secondary schools, language learning resources, ESL and the learning lab, languages in elementary schools, media centers, and related topics.

Subject of Articles: Because chalkboard, textbook, and flashcards have withstood the test of time-whereas their more exotic sibling technologies often have not-technological subjects published in J.E.T.T. span the spectrum of "little media-big media" in foreign, second, and native language teaching and learning.

Because drill-and-practice, role-play, and songs are effective educational practices in the language classroom, pedagogical topics published in J.E.T.T. span the spectrum from the traditional to the avant-garde methodologies in language teaching and learning.

The most suitable subjects for the pages of J.E.T.T. are those which tell of "how-to" integrate effective learning/teaching research, theory, and practice with appropriate print, electronic, audiovisual, or magnetic media technologies. J.E.T.T. specializes in practices and products for today's language learning.

Form of J.E.T.T. Manuscripts: J.E.T.T. uses the Publication Manual of the American Psychological Association (APA), 1983, as its style manual. Copies may be ordered from the Order Department, APA, Box 2710, Hyattsville, MD 20784. Currently, over 200 non-APA journals use-in whole or in part-the APA style manual. J.E.T.T. modifies this style whenever necessary.

Preparation of Manuscripts Submitted to J.E.T.T. The instructions for manuscript preparation are intended as an aid to assist authors in communicating clearly.

Length: As a rule of thumb, three doublespaced, typed manuscript pages equal one printed journal page. J.E.T.T. welcomes any article long enough to cover the subject but short enough to keep it interesting. The average length of manuscripts submitted to J.E.T.T. is $10-14$ pages.

Title: The title of a manuscript should literally "pull" the reader into the subject of the article by stating concisely and with attention-grabbing style the "gist" of the main idea or issue under discussion. Authors should avoid any word that does not help pull the reader into the topic. The recommended length of a manuscript title is 12 to 15 attention-grabbing, topic-enlightening words.

Author's Name/Affiliation: In addition to the title, the Title Page also lists the author's name 
(First Name, Middle Initial, and Last Name) with all professional titles omitted. (See pages 23 and 148 of APA publication manual). Below his or her name, the author types the name of the institution where the work or manuscript was done; when there is no institutional affiliation, the author types the city and state of residence.

Running Head: On the bottom of the Title Page, the author types the running head-an abbreviated title with a maximum of 50 spaces, including letters, punctuation, and spaces.

Abstract: All manuscripts submitted to J.E.T.T. must have an abstract-a brief, succinct summary recapitulating the main ideas or findings of the manuscripts. Generally, an abstract consists of 75-150 words; it is written in a clear, vigorous, and informative style; authors should use the active instead of the passive voice.

Typing: Manuscripts must be typed on high quality, white bond paper, 8.5" x 11" (22cm x 28 $\mathrm{cm}$ ) and double-spaced throughout.

Margins: Top, bottom, and sides are 1.5" (4 $\mathrm{cm})$ without exception.

Separate Pages: Title Page, Abstract, Tables, Author Acknowledgements, etc., must all be typed on separate pages.

Print: The entire manuscript must be typed; only letter-quality computer print-outs are acceptable.

Number of Manuscripts: Authors must submit the original and three clean copies; the three copies should not show author identification.

References: All citations in the manuscript must appear in the reference section typed at the end of the manuscript; all references listed at the end of the manuscript must appear in the text.

Hyphenation: Authors should not hyphenate words at the right-hand margin; leave space and begin a new line or go slightly beyond margin.

Dictionary: J.E.T.T. uses Webster's New Collegiate Dictionary by G. C. Merriam Company, Springfield, Massachusetts as the final arbiter on American English.

How to Submit a Manuscript to J.E.T.T.

Submit the original and three clean photocopies; include glossy prints of any figures.
Carbon copies and non-letter quality computer print-outs are unacceptable.

Cover Letter: Enclose a short cover letter when submitting a manuscript to the editorial offices of J.E.T.T. The cover letter should include the following information: specific information about the manuscript such as title, number of pages, number of tables or illustrations, and copies of all applicable copyright releases for copyright protected materials; include telephone number and complete address.

Simultaneous Submissions: A manuscript that has been submitted to another publication simultaneously will not be considered for publication in J.E.T.T.

Copyright: When a manuscript is accepted for publication in J.E.T.T.-each issue of which is copyright protected under the Copyright Laws of the United States-the author will receive a Copyright Transfer Form by which the author transfers all rights to J.E.T.T. In the event the author wishes to re-print any portion of his or her article as it appeared in J.E.T.T., he or she must ask for written permission from the Editor. An article accepted for publication will not be published unless and until the Editor receives the signed copyright transfer form.

Manuscript Receipt Response: When a manuscript is received in the editorial offices of J.E.T.T., the editor will respond with an acknowledgement within 48 hours unless extraordinary circumstances prevent acknowledgement.

Blind Review: J.E.T.T. adheres to a "blind" review of all manuscripts. Identification of manuscript author should appear only on the Title Page; all other pages should be labeled with the short title and page number only in the upper right-hand corner of each manuscript page. The peer review process takes approximately 10-12 weeks; on occasion and at the discretion of the Editor, the peer review process may be extended to give a reader more time or make allowances for the international mail.

Reviewers: The reviewers who participate in the J.E.T.T. peer review process of all manuscripts are national and international professionals in the field; each evaluates manuscripts in his or her area(s) of expertise. Reviewers are 
selected by the editors on the basis of their willingness to serve the publication in this important capacity and on the record of their service to the profession.

MANUSCRIPT SUBMISSION ADDRESS: Editor, J.E.T.T., 304C Moore College Building, University of Georgia Language Laboratories, University of Georgia, Athens, Georgia 30602 U.S.A.

\section{Product Submission for Review}

All items submitted for review must be submitted as a complete unit; that is, all supplemental and peripheral items that go with the item for review must accompany the submission. An item that has been submitted simultaneously for review elsewhere must be identified as such.

All items must be properly packaged, insured, and sent to: J.E.T.T., 304C Moore College Building, Language Laboratories, University of Georgia, Athens, Georgia 30602 U.S.A.

The Journal of Educational Techniques and Technologies considers for review the following in the area of practices and products for today's language learning: Books, Audio Programs, Film, Software, Hardware, Audio-Visual Materials, Video, and Related Materials.

The opinions expressed in the review are those of the author(s) and do not in any way represent the expressed or implied endorsement of the Editors or The International Association For Learning Laboratories (IALL).

Before sending an item for review, notify the Editors-by mail or telephone-of your intention to do so. Items will be returned to producers only upon request at the time of submission.

\section{Specific Submission Procedures}

Film: One (1) copy of the film, together with its supplemental materials must be submitted to J.E.T.T. The company or film maker submitting the film for review must include the following: price, intended target audience, if, when, and where the film has already been used in learning applications. The company or film maker submitting the film must include a biographical sketch of the person(s) responsible for producing the film.
The film review process takes approximately 12 weeks. The Editor reserves the right to lengthen the review process as circumstances warrant and to determine if, when, and in which issue the review of the film will appear.

J.E.T.T. reviews films from national and international film sources, small production companies, and individuals on the theme of practices and products for today's language learning. The preferred film format is $16 \mathrm{~mm}$, although J.E.T.T. will review other formats as well.

Video: One (1) copy of the video program, together with its supplemental materials must be submitted to J.E.T.T. The publisher or person submitting the video must indicate if, when, and where the program has been reviewed, the target audience if it is already being used in language learning applications, and the cost.

The publisher or person submitting the video program must include a biographical sketch of the person(s) who made the video.

J.E.T.T. considers for review video in the area of practices and products for today's language learning. Video sent to J.E.T.T. for review will be sent to reviewers judged by the Editors as capable of reviewing both content and treatment.

The video review process takes approximately 10 weeks. The Editor reserves the right to lengthen or shorten the review process and to determine if, when, and in which issue the review will appear.

The preferred format is NTSC VHS; however, J.E.T.T. also reviews multi-standard PAL, SECAM video programs in $V H S$. Other formats are also welcome, but their review depends on J.E.T.T. locating qualified reviewers with the appropriate equipment.

Software: One (1) copy of the software program, together with its supplemental and peripheral materials must be submitted to the editorial offices of J.E.T.T.

If demonstration discs are submitted, they will be evaluated simply as that-demonstration discs. If the publisher wishes to send only one lesson of a multi-lesson software program, the lesson must be truly representative of the entire program; the evaluation, however, will be made specifically on the lesson submitted. 
J.E.T.T. accepts software programs that run on the IBM and IBM compatibles, Apple, Tandy, and Commodore. For programs that run on $\mathrm{PCs}$ other than the above-mentioned, J.E.T.T.' cannot guarantee that its reviewers have the specific PC; the Editors will attempt to find the required hardware, however.

Software programs are submitted to professionals in the field who are judged by the Editors as capable of evaluating the submitted programs.

J.E.T.T. accepts for review only software programs in the area of practices and products for today's language learning from national and international publishers, program producers, and individuals.

The software review process takes approximately 14 weeks. The Editor reserves the right to lengthen or shorten the review process and to determine if, when, and in which issue a software review will appear.

For computer software, please indicate the following:

Courseware name

Application

Instructional method

Vendor

Cost

Copy policy

Equipment

PC memory required

Prerequisites

Hardware: J.E.T.T. accepts for review hardware applicable in the area of practices and products for today's language learning. The hardware must be carefully packed, insured, and sent via a carrier determined by the vendor. Before sending hardware, notify the editorial offices of J.E.T.T. of the impending submission.

Hardware submitted for review is submitted to professionals in the field who are judged qualified to review the hardware in question. The Editor determines if, when, and in which issue a hardware review will appear.

Audio-Visual Materials: J.E.T.T. accepts audio-visual print and electronic materials in the area of practices and products for today's language learning. A complete set of the A-V materials must be sent to the editorial offices of J.E.T.T.
The A-V materials will be sent to professionals in the field who are judged capable of evaluating the materials. The review process takes approximately 10 weeks. The Editor reserves the right to determine if, when, and in which issue a particular A-V review will appear.

J.E.T.T. accepts for review A-V materials produced by national and international publishers, companies, and individuals.

Audio Programs: One (1) copy of the complete audio program and its supplemental materials must be submitted to J.E.T.T. The publisher or person submitting the audio program must indicate the language applications for which this program is designed and the circumstances under which it may be used, including copy policy and cost of purchase.

J.E.T.T. reviews audio programs from national and international publishers, little known or small companies, and individuals in the area of practices and products for today's language learning.

The Editor reserves the right to determine if, when, and in which issue a particular audio review will appear. The review process takes approximately 10 weeks and may be lengthened or shortened by the Editor as circumstances warrant.

Books: Three (3) copies of the book, together with its supplemental materials, must be submitted to J.E.T.T. Books sent for review will be returned only upon request at the time of submission.

Publishers or persons submitting books for review must indicate the cost of the book and each supplemental item.

The book review process takes approximately eight weeks; the Editor reserves the right to lengthen or shorten the process as circumstances warrant, and to determine if, when, and in which issue a particular book review will appear.

J.E.T.T. reviews books from national and international publishers, little known and small presses, and self-publishers in the area of practices and products for today's language learning. 